\title{
Flexible ERP for Construction Company with Petri Net Model
}

\author{
Masca Indra Triana ${ }^{1^{*}}$, Berlian Al Kindhi ${ }^{2}$ \\ ${ }^{1}$ Program of Civil Engineering, Universitas 17 Agustus 1945 Surabaya, Surabaya \\ ${ }^{2}$ Department of Electrical Automation Engineering, Institut Teknologi Sepuluh Nopember, Surabaya \\ *Corresponding Author \\ E-mail: masca.indra@untag-sby.ac.id*
}

\begin{abstract}
Prospectively, the existence of the construction service industry, both small and large scale, has strategic value for Indonesia, considering that the proportion of its role is quite large and involves the large number of workers involved in the implementation of a construction project. From the above statement, it can be concluded that construction service companies have a positive impact on economic development. But in reality, the implementation of a construction service business has several obstacles and problems. According to the Report on Construction Development "BAPEKIN" in the socialization of Law no. 18/1999 and the Implementation Regulations for construction services, there are several problems that occur in the Business Potential or Conditions of Construction Services in Indonesia. Generally, these problems are the unrealized quality of construction, timeliness of implementation, and efficiency of resource utilization as planned. The unequal position between Service Users and Service Providers in rights and obligations is fair and harmonious. To overcome the above problems, one solution is to develop a technology that can integrate the needs of various construction companies, facilitate the company's business processes so that the company's goals can be maximally achieved. ERP is an enterprise information system designed to coordinate all resources, information, and activities required for a complete business process. ERP systems are based on databases and modular software designs.
\end{abstract}

Keywords: Construction Company, ERP, Petri Net Model.

\section{INTRODUCTION}

The construction company business includes three stages, namely Engineering, Procuring, and Contracting (EPC). These three stages of work can be one tender or separate. A construction company can only work on one process or all those[1]. There are also several types of businesses in the construction industry, including EPC, infrastructure (bridges, roads, public facilities), and buildings. In addition, construction work can be divided into two types, namely made to stock and made to order[2]. Made to order means that a company will do a job when it receives a contract offer, for example, a bridge infrastructure development project. Meanwhile, made-tostock means that a company has carried out the EPC process without waiting for an offer and the results of the EPC will be sold, for example, housing development.

Construction companies have complex business process problems and not all of them have the same business processes, while ERP design requires a mature concept based on these business processes. Enterprise Resource Planning (ERP) is a system that connects every component of a company's business process in detail. For example, if there are five construction companies that have different business processes, the ERP module will be designed according to that business 
process[3]. For this reason, a framework is designed that can implement the business processes of each company and process them into a module. Users can flexibly design and add ERP modules and system frameworks that will execute them into the program. So that we get an ERP system that can handle multi-tenancy SaaS.

In describing a certain research procedure or process, sometimes it is not enough to only use words or algorithms[4]. More detailed statements or rules are also needed. One of the most commonly used is a flowchart. A flowchart is a chart that shows the flow of a system's procedures logically. However, the constraint when building a flowchart is that the chart can only describe one system, we cannot see the relationship between processes that use the same data source or vice versa. In addition, flowcharts also cannot show how time affects the stages of the process. Flowcharts can only describe a process serially. In fact, these processes often occur simultaneously if there is no special dependency, which can be analogous to a parallel system, where each data can be used by several processes or one process can use a lot of data running simultaneously. Petri Net or what is called Place Transition Net is one of the models to describe concurrency and hosts in a distributed system. Petri nets are similar to State Transition Diagrams which depict real-time system behavior and change with the user but are more robust in mathematics and notation[5].

Data processing can be done in graph form, namely by graph clustering. A clustering graph is a technique of grouping graphs into clusters where data with relatively the same character will be grouped into one cluster[6]. To get the cluster, the algorithm from the clustering graph will compare the two eigenvalues of a node based on the similarity of the information so that it produces two spectral directions. The graph model was chosen because it can model the relationships between objects and provide easy-to-understand visualization. Information on each ERP submodule can be represented as a node and can be linked to nodes others who have similarities with other nodes. Then the connected nodes will be grouped into a number of clusters using a graph clustering algorithm.

The main key of ERP is the connection and integration between each part of the business process so that ERP is able to provide accurate analysis and avoid fraud in a company's business processes. Construction companies have a variety of business processes that differ from one another, both in terms of implementation and organizational structure. This can lead to fraud in the middle of a business process that is often carried out on a project. This study proposes a flexible ERP model that can help its business processes as needed by the construction company so that it can increase efficiency in the company.

\section{METHODOLOGY}

\section{A. Construction Company}

A construction company is a business engaged in the construction of physical infrastructure, facilities, and infrastructure for the benefit of the community, in this case, according to the request of the client[7]. As a business that produces products in the form of physical infrastructure, construction companies have a very vital role in both regional and national growth and development. A construction company is a business with very high risk and full of uncertainty with profits that can only be obtained after the project is completed. The market for the construction industry is strongly influenced by buyers because the interests of buyers are highly protected by the presence of supervisors, insurance companies, and binding banks. 
A construction company has a very conservative contract value and selling price but has a very fluctuating production cost or budget[8]. The processing time schedule and quality standards are always determined by the client or buyer. The construction or construction process tends to change due to differences in location and planning according to the project they get. The decision making of a client to cooperate with the construction company is strongly influenced by the company's reputation[9]. In addition, construction project implementation has a high probability of accidents at work because some of the activities are carried out in the field. So that every construction company is obliged to implement work safety procedures and insurance for each worker.

\section{B. Petri Net Markup Language for flexible ERP}

Petri Net Markup Language is an xml-based language that represents a series of activities. Petri Net is a notation that has been widely used because of its easy-to-understand structure[10]. Petri Net is commonly used in the analysis and design phase of a business process. The Petri Net structure consists of several parts. In Figure 1, a circle is a place. The place is the place of the token when doing activity traversal. Then the rectangular part is a transition. Transition is a representation of activity. Finally, the arrow that connects the place and transition is an edge or arc. Edge shows the movement from one activity to another.

Structural similarity is the value of similarity between business process models by looking at the structure or shape[11]. The structure is seen from each part of the existing model. Because the model used is Petri Net, the part of the model consists of a transition, place, and edge. In transition and place by comparing the identifier they have. Meanwhile, the edge is compared by looking at the linked source and target. Then the similarity value can be calculated by Equation 1 .

$$
\operatorname{sim}=\frac{\text { the number of equal part }}{\text { the number of equal part }+ \text { the number of idfferent part }}
$$

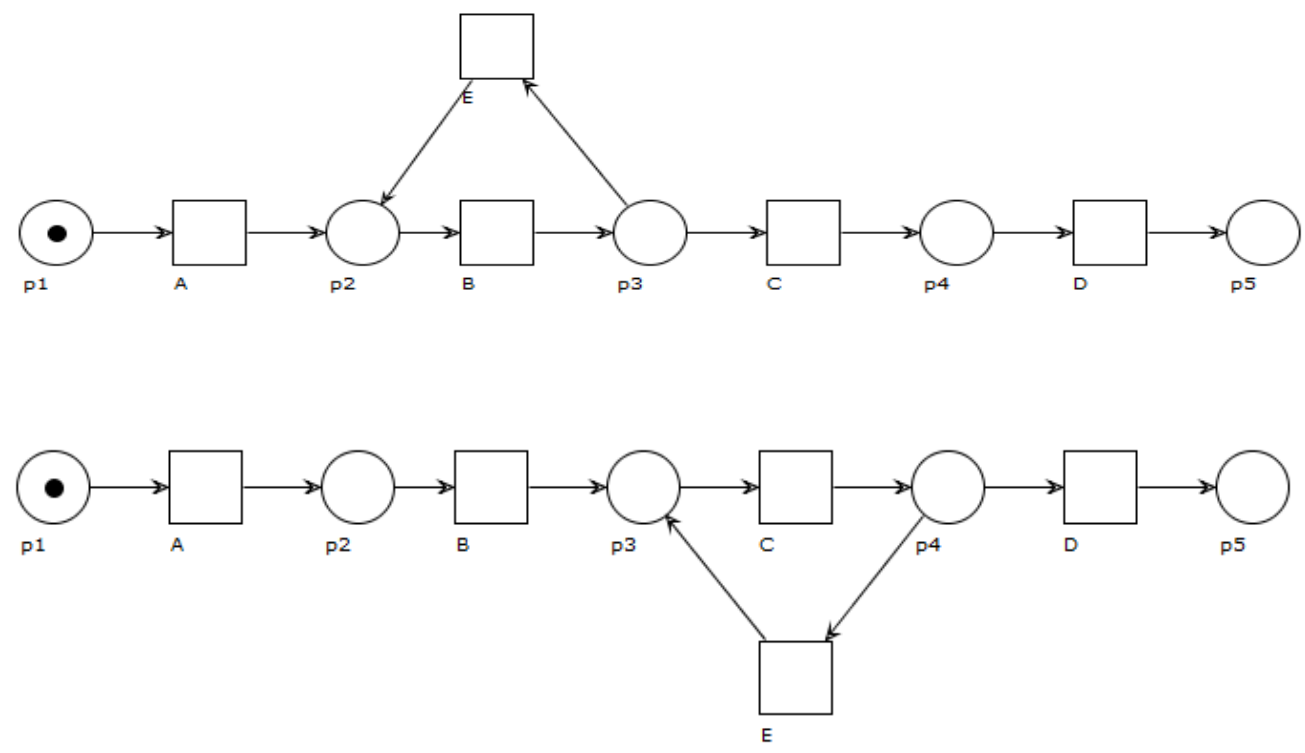

Figure 1. Petri Net Similarity

In Figure 1, it can be seen that the difference is only in activity $\mathrm{C}$ and activity $\mathrm{D}$. So, transition and place have the same number of 10 . Then for the edge, there are differences in the edges both 
entering and leaving activity $\mathrm{E}$ in each model. So that the edge has the same number of 8 and the difference is 4 . So that the value of the similarity obtained is $18 / 22=0.818$.

\section{Clustering with graph partition approach}

The grouping method used is based on the distance between 2 entities which is similar to graph partition. This method is usually used when the objects that are grouped are difficult to represent in a mathematical form. The distance used in the grouping process is based on the similarity of each model. A collection of business processes that have a high degree of similarity will of course become one group.

In determining the cluster with the graph partition approach, the first step we take is to determine the threshold value then calculate the similarity between the models, this calculation process will be repeated until the last model and compare the similarity value of the model with the threshold value. If there are two models whose similarity value is above the threshold value, the model will be given an edge to connect the two. A model that is not connected to any model means that it does not belong to any cluster. One graph formed shows one cluster so that the number of clusters is the same as the number of graphs formed.

\section{RESEARCH RESULT AND DISCUSSION}

\section{A. Result}

Unlike standard corporate business processes, construction company business processes have very unique and unstructured changes. In terms of types, construction companies are divided into two types, namely made to stock and made to order. Meanwhile, from the types of work, there are three groups, namely EPC (engineering, procuring, contracting), infrastructure (roads, bridges, public facilities, housing), buildings (office buildings, fabrication, universities).

For 3M (man, machine, money) in a construction company, it is also uncertain in every production. For example, for a wardrobe company, to make a wardrobe the materials needed are clear, namely the amount of wood, cupboard handles, keys, and the number of employees who make it. While construction companies, although the types of work are the same (for example building), the production process is different depending on the location of the building to be erected, the design of the building to be made, the specifications of the materials. If the design changes, the land contours are different, this will result in changes to budgets, man, machine, schedule, and other procedures.

Table 1. Similarity Matrix

\begin{tabular}{|l|l|l|l|l|l|l|}
\hline & $\mathrm{N} 1$ & $\mathrm{~N} 2$ & $\mathrm{~N} 3$ & $\mathrm{~N} 4$ & $\mathrm{~N} 5$ & $\mathrm{~N} 6$ \\
\hline N1 & 1 & 0.65 & 0.75 & 0.42 & 0.23 & 0.18 \\
\hline N2 & 0.65 & 1 & 0.72 & 0.58 & 0.22 & 0.19 \\
\hline N3 & 0.75 & 0.72 & 1 & 0.42 & 0.19 & 0.13 \\
\hline N4 & 0.42 & 0.58 & 0.42 & 1 & 0.55 & 0.41 \\
\hline N5 & 0.23 & 0.22 & 0.19 & 0.55 & 1 & 0.83 \\
\hline N6 & 0.18 & 0.19 & 0.13 & 0.41 & 0.83 & 1 \\
\hline
\end{tabular}

Table 2. Adjacency Matrix

\begin{tabular}{|c|c|c|c|c|c|c|}
\hline & N1 & N2 & N3 & N4 & N5 & N6 \\
\hline N1 & 1 & 0 & 1 & 0 & 0 & 0 \\
\hline N2 & 0 & 1 & 1 & 0 & 0 & 0 \\
\hline N3 & 1 & 1 & 1 & 0 & 0 & 0 \\
\hline
\end{tabular}




\begin{tabular}{|l|l|l|l|l|l|l|}
\hline N4 & 0 & 0 & 0 & 1 & 0 & 0 \\
\hline N5 & 0 & 0 & 0 & 0 & 1 & 1 \\
\hline N6 & 0 & 0 & 0 & 0 & 1 & 1 \\
\hline
\end{tabular}
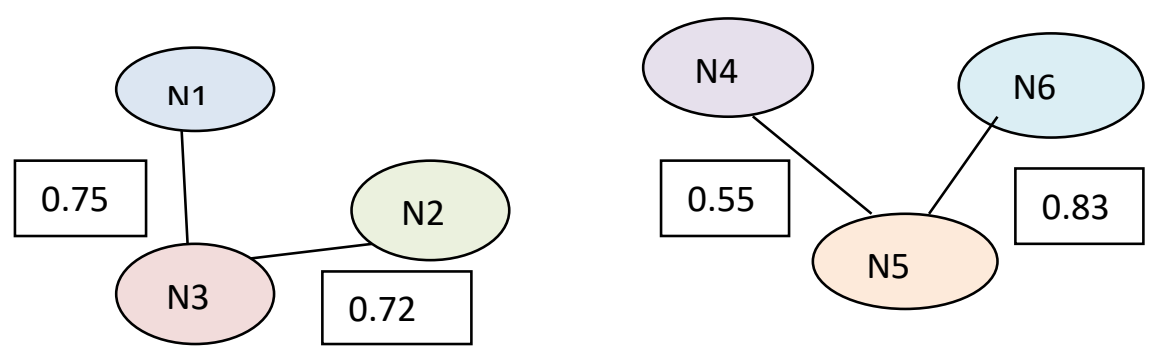

Figure 1. Clustering result of Similarity Matrix and Adjacency Matrix

There are many variables that change irregularly in a construction business process and almost every production process has a different flow and $3 \mathrm{M}$. The dependency of these variables is also based on uncertain factors. After understanding how business processes occur in construction companies, the results of this analysis will be used as the basis for making an ERP module. What ERP modules are needed in accordance with the business processes and derivatives of these modules, namely up to the sub-module analysis stage.

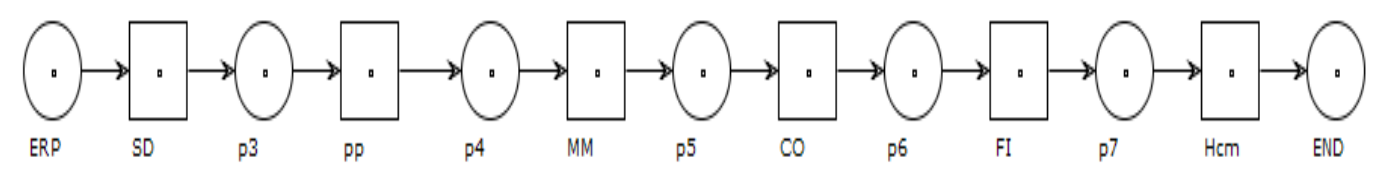

Figure 2. ERP five main business processes in Construction Company

ERP has five main business processes, these five main business processes can occur at the same time or sequentially. So in the picture above is depicted as an interconnected circle. Of the five main business processes, there are variations in them. Underneath these variations can still be reduced to a new variation called Dependency of Variation.

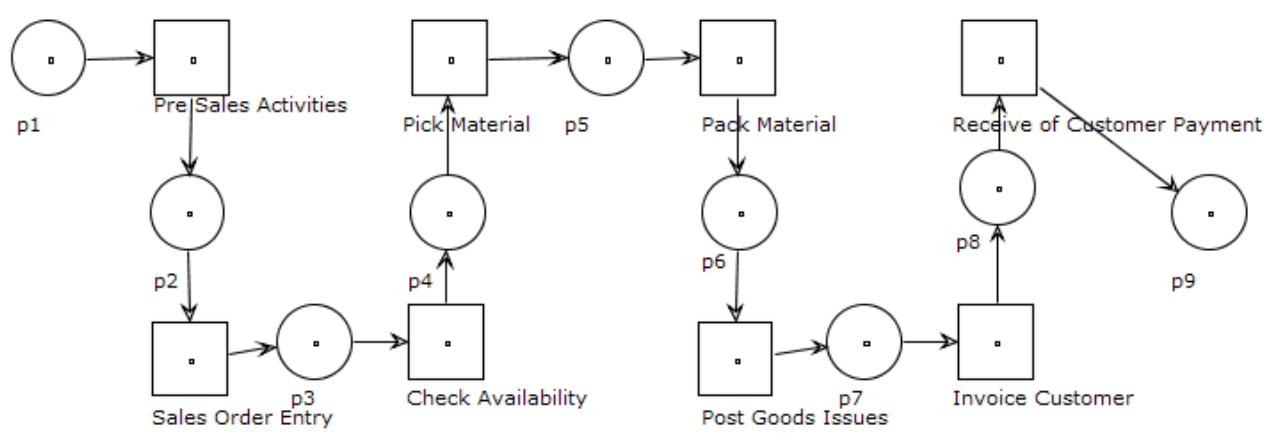

Figure 3. Sales Order (SD) Sub Module

The first business process is the Sales Order, which is the process by which the products from the company are marketed and product purchase requests. The second process is Production Planning. After obtaining a production request, the company will plan the production process. 
The Material Management business process can occur after or simultaneously with Production Planning. Material Management functions to check whether the material stock needed for the production process is still sufficient or if you have to make another purchase. After the production process is planned and the material for production is sufficient, the next process is to oversee the production process, this stage of the business process is often referred to as Controlling. Controlling records problems that occur during the production process, for example, there is a human error and reports (confirmed) when the product has been made. The last business process is finance, which is the process of financial recording. The finance business process can occur simultaneously with every stage of the other business processes. For example, it can occur simultaneously with Material Management when purchasing new materials.

\section{B. Discussion}

Basically, not all construction companies have the same series of business processes in carrying out their activities. However, it is very inefficient to design an ERP system that is detailed enough for only one company. Therefore we need a framework for ERP that is able to combine modules according to user requests, in this case, according to the business processes of each company. So that one ERP application can be used by multi-tenancy and configurable.

The dependency of these variables is also based on uncertain factors. For example, whether the land contours are good or need fill (which causes the node Schedule and budget to change). For example, if the building design includes a green building, it can change the value in the vendor module, such as the amount of brick material, less glass, more. Or if the production process will be done alone or in a subcontract, which will result in the business process in the Schedule, budget, production planning, material management modules also changing. From the analysis of these problems, it can be concluded that to determine a construction business process, the parent of the business process is the Project List. From the project, the types of work can be grouped, then they can be derived according to their respective business processes as can be seen in Table 3.

Table 3. Division of Construction Company Business Processes

\begin{tabular}{|c|c|c|c|}
\hline \multirow{3}{*}{ EPC } & Variabel & Made to Stock & Made to Order \\
\hline & Engineering & & $\mathrm{X}$ \\
\hline & Procuring & & $\mathrm{X}$ \\
\hline & Contracting & & $\mathrm{X}$ \\
\hline \multirow{3}{*}{ Infrastructure } & Housing & & $\mathrm{X}$ \\
\cline { 2 - 4 } & Road & & $\mathrm{X}$ \\
\hline & Bridge & & $\mathrm{X}$ \\
\hline & Public Facilities & & $\mathrm{X}$ \\
\hline & Building (tall building) & & $\mathrm{X}$ \\
\hline & Universities building & & $\mathrm{X}$ \\
\hline & Fabrication & & $\mathrm{X}$ \\
\hline & Refinery and & & $\mathrm{X}$ \\
\cline { 2 - 4 } & warehousing & & \\
\hline & & & \\
\hline
\end{tabular}

After analyzing and dividing the construction business process model, it can be obtained business process variations from each module. Figure 5 is an example of the results of the calculation of the similarity of the construction company business process in the sales on delivery 
submodule. The process of calculating the similarity uses the graph partitioning method which is implemented into the Petri net model. There are five extraction models for variations in the sales on delivery submodule, for the full variety of extraction results we present in the appendix.

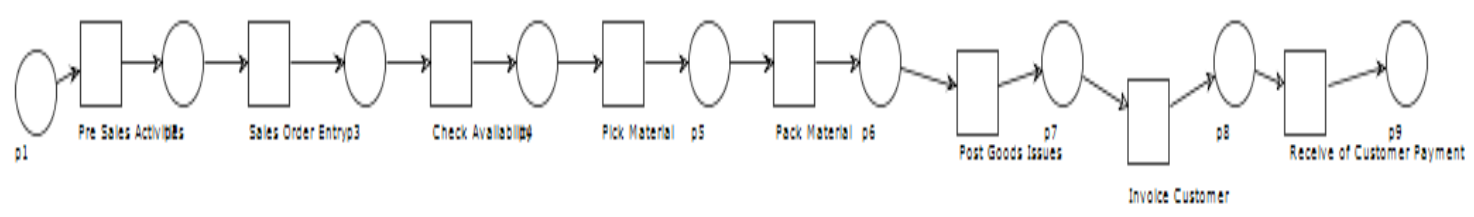

Figure 4. The results of variations in the sales on delivery (SD) sub-module use a graph clustering approach

\section{CONCLUSIONS}

Construction companies have varied business processes and even within one company, it may have different business processes for one project to another. This varied business process can be a factor in the occurrence of fraud in the implementation of work. In this study, we propose the use of flexible ERP in which each module to sub-module is able to integrate flexibly according to the needs of business processes. We calculate the similarity of information from business processes using the clustering graph approach implemented with the Petri net model. Petri net model facilitates the analysis process of orchestration for each variant. With the flexible selection of ERP modules, it is hoped that a construction company will be able to develop modules according to their respective needs but still integrated them into one ERP. So that the cheating process can be prevented and wasteful activities on a project can also be avoided.

\section{REFERENCES}

[1] J. Dai, Y. Wei, and W. Liu, "Application of the supply chain in the construction business based ERP," 2016, doi: 10.1109/ICSGEA.2016.30.

[2] A. S. Girsang, S. M. Isa, H. Saputra, M. A. Nuriawan, R. P. Ghozali, and E. R. Kaburuan, "Business Intelligence for Construction Company Acknowledgement Reporting System," 2019, doi: 10.1109/INAPR.2018.8627012.

[3] I. Zafar, F. Azam, M. W. Anwar, B. Maqbool, W. H. Butt, and A. Nazir, "A novel framework to automatically generate executable web services from bpmn models," IEEE Access, 2019, doi: 10.1109/ACCESS.2019.2927785.

[4] K. Shafi et al., "Measuring performance through enterprise resource planning system implementation," IEEE Access, 2019, doi: 10.1109/ACCESS.2018.2884900.

[5] R. Davidrajuh, "Extracting petri modules from large and legacy petri net models," IEEE Access, vol. 8, pp. 156539-156556, 2020, doi: 10.1109/ACCESS.2020.3020213.

[6] W. Zhang and M. Zhang, "Graph Partitioning Algorithm with LSH: Poster Extended Abstract," in Proceedings - IEEE International Conference on Cluster Computing, ICCC, Oct. 2018, vol. 2018-September, pp. 166-167, doi: 10.1109/CLUSTER.2018.00053.

[7] C. L. Giron, "Enterprise Architecture Model oriented to Architecture, Engineering and Construction Industry : Integration of Geospatial Concepts in a Specific Framework," in Iberian Conference on Information Systems and Technologies, CISTI, Jun. 2020, vol. 2020June, doi: 10.23919/CISTI49556.2020.9140841. 
[8] M. S. Bajjou and A. Chafi, "Towards implementing lean construction in the Moroccan construction industry: Survey study," in Proceedings of the 2018 International Conference on Optimization and Applications, ICOA 2018, May 2018, pp. 1-5, doi: 10.1109/ICOA.2018.8370556.

[9] A. Minasowicz and P. Nowak, "Leonardo da Vinci programs - Useful tool for improvement of the European construction companies performance," 2016.

[10] W. Peng, J. Zhang, and J. Zhang, "Novel dynamic evidential petri net for system reliability analysis," J. Syst. Eng. Electron., vol. 28, no. 5, pp. 1019-1027, Oct. 2017, doi: 10.21629/JSEE.2017.05.20.

[11] X. Zhang, Y. Du, L. Qi, and H. Sun, "An Approach for Repairing Process Models Based on Logic Petri Nets," IEEE Access, vol. 6, pp. 29926-29939, May 2018, doi:

10.1109/ACCESS.2018.2843137.

Appendix:

The results of variations in the sales on delivery (SD) sub-module use a graph clustering approach
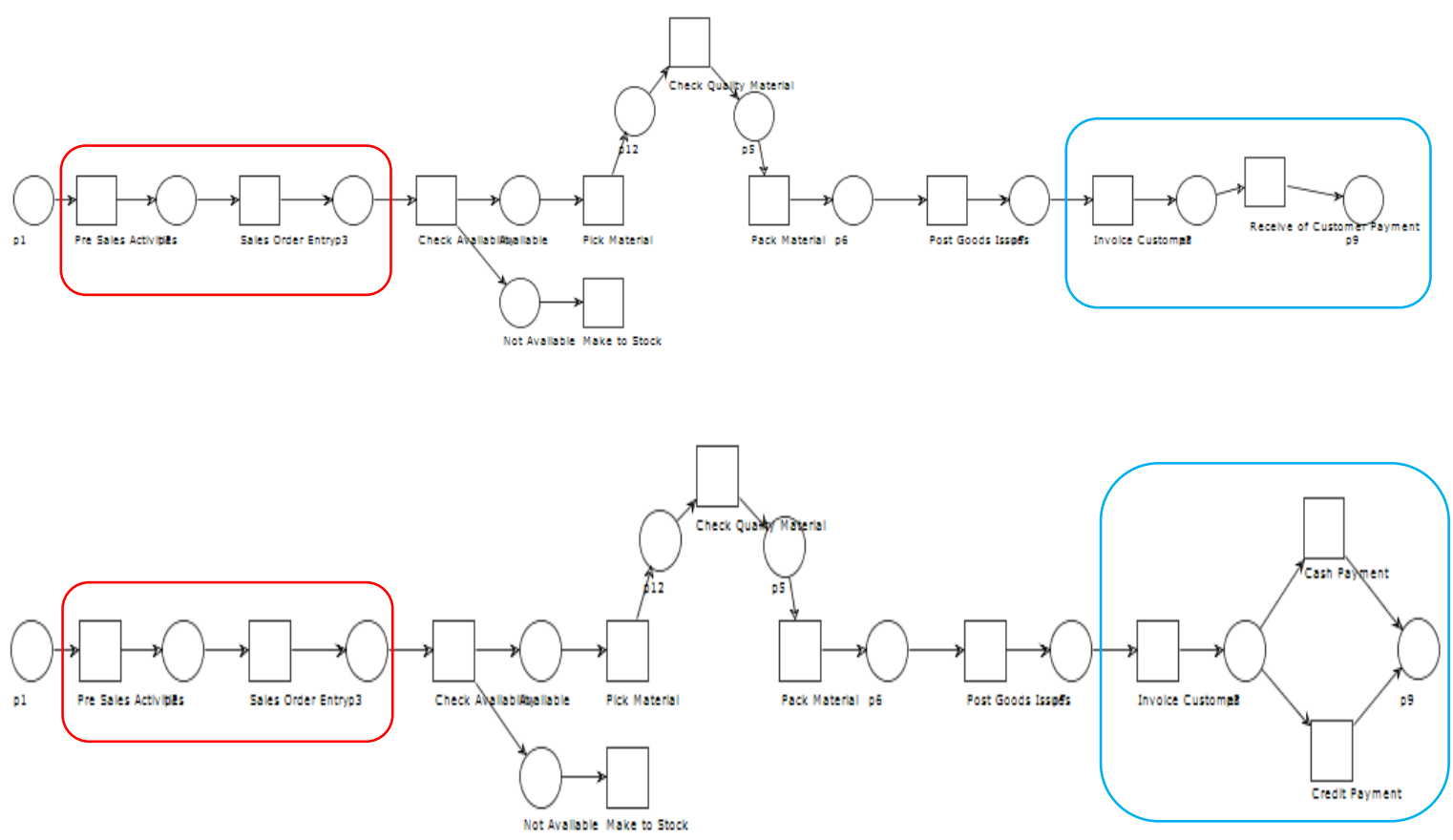

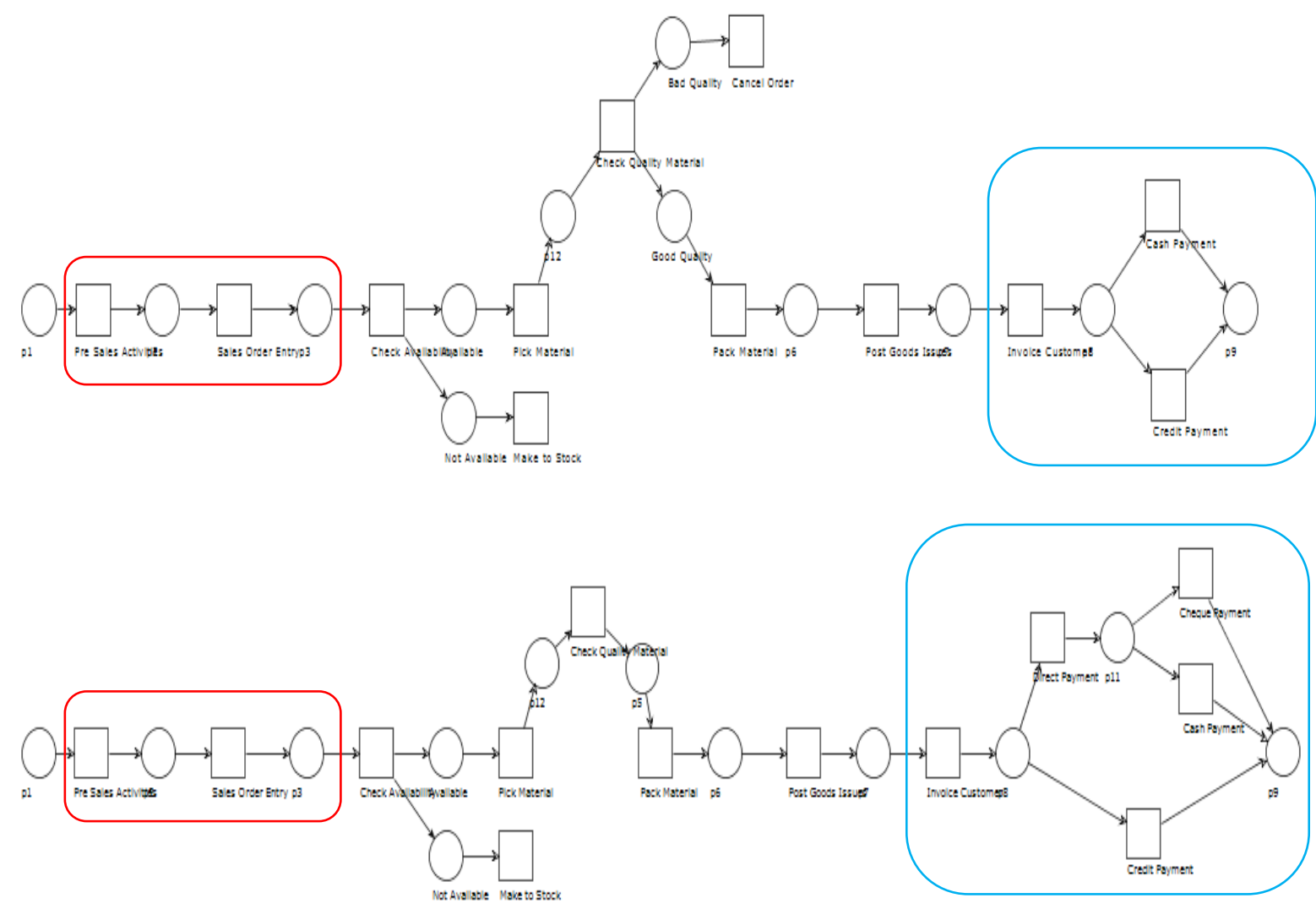